\title{
Cooperative Learning in Rural Mathematics Classrooms: Interactions of Instructional Coaching, and Achievement
}

\author{
Joanna Burt-Kinderman
}

Follow this and additional works at: https://researchrepository.wvu.edu/etd

\section{Recommended Citation}

Burt-Kinderman, Joanna, "Cooperative Learning in Rural Mathematics Classrooms: Interactions of Instructional Coaching, and Achievement" (2015). Graduate Theses, Dissertations, and Problem Reports. 5287.

https://researchrepository.wvu.edu/etd/5287

This Thesis is protected by copyright and/or related rights. It has been brought to you by the The Research Repository @ WVU with permission from the rights-holder(s). You are free to use this Thesis in any way that is permitted by the copyright and related rights legislation that applies to your use. For other uses you must obtain permission from the rights-holder(s) directly, unless additional rights are indicated by a Creative Commons license in the record and/ or on the work itself. This Thesis has been accepted for inclusion in WVU Graduate Theses, Dissertations, and Problem Reports collection by an authorized administrator of The Research Repository @ WVU. For more information, please contact researchrepository@mail.wvu.edu. 
Cooperative Learning in Rural Mathematics Classrooms:

Interactions of Instructional Coaching, and Achievement

\author{
Joanna Burt-Kinderman \\ Thesis submitted to the College of Education and Human Services \\ at West Virginia University \\ in partial fulfillment of the requirements for the degree of \\ MASTER OF ARTS in \\ Secondary Education \\ Johnna Bolyard, Ph.D., Chair \\ Reagan Curtis, Ph.D. \\ Matthew Campbell Ph.D.
}

Department of Curriculum and Instruction / Literacy Studies

Morgantown, WV

2015

Keywords: Cooperative Learning, Mathematics, Rural, Student-Centered, Copyright 2015 Joanna Burt-Kinderman 


\section{ABSTRACT \\ Cooperative Learning in Rural Mathematics Classrooms: Interactions of Instructional Coaching, and Achievement}

\section{Joanna Burt-Kinderman}

Cooperative learning in school mathematics has been widely studied. However, variation is found in efficacy of this approach. This study examines the particular fit of a cooperative learning approach in rural mathematics classrooms. Research centers on two rural sixth-grade mathematics classrooms whose teachers have had varying degrees of experience in and support for a student-centered cooperative approach to mathematics. This study examines the overall effect of cooperative learning in this setting, then searches for differences in outcomes that may correlate with differences in experience, support, and teacher training in cooperative learning processes. Throughout the school year, benchmark measures of students' mathematics achievement were taken at three different intervals. Results from repeated-measures ANOVA are reported. Students showed significant growth in achievement in both cooperative-learning classrooms. There were not significant differences found overall on mathematics achievement between the classrooms at the two schools. However, the interaction effect of treatment and time approached significance $(p=.051)$. Differences in the shapes of the growth in mathematics achievement over time between groups are explored, and implications for further research are discussed. 


\section{Acknowledgement}

My thanks to my advisor, Johnna Bolyard, for her guidance, support and careful edits. Thanks to Reagan Curtis for whiteboard diagrams that helped lasso the curious into the possible, and to Matthew Campbell for respectful edits as well as pragmatic reassurance and carefully crafted encouragement at just the right moment.

Thanks as well to David Loomis for your patient fellowship and thorough advice in dancing with analytic assumptions.

Huge thanks to my family for your unwavering support each time I decide to do things the hard way. Any bits I have to contribute to this world are thanks to you three. 


\section{Table of Contents}

Abstract iii

Table of Contents $\quad$ iv

$\begin{array}{ll}\text { Introduction } & 1\end{array}$

$\begin{array}{ll}\text { Literature Review } & 1\end{array}$

Place-Based Need: Examination of Setting 1

Cooperative Learning: History and Related Literature 10

Cooperative Learning: Best Practices and Approaches $\quad 16$

Instructional Coaching: How Best to Build System-Wide Change 19

$\begin{array}{lr}\text { Objective } & 21\end{array}$

$\begin{array}{ll}\text { Method } & 21\end{array}$

$\begin{array}{lr}\text { Participants } & 21\end{array}$

$\begin{array}{lr}\text { Research Design } & 24\end{array}$

$\begin{array}{lr}\text { Results } & 29\end{array}$

$\begin{array}{ll}\text { Discussion } & 32\end{array}$

$\begin{array}{ll}\text { Limitations } & 32\end{array}$

Conclusions and Next Steps $\quad 39$

References $\quad 42$ 
Cooperative Learning in Rural Mathematics Classrooms: Interactions of Instructional Coaching, and Achievement

I am a district-wide mathematics instructional coach in a resource-scarce state and district. In the face of calls for huge changes in instruction and poor achievement results both statewide and in my particular district, I jumped at the possibility of inclusion in an Investing In Innovation Scale-Up study examining the use of a cooperative learning framework for middle school mathematics. This program came complete with materials, training, regular coaching visits from a regional coordinator and a research-based (Slavin et al., 2009) framework for teaching mathematics. In this study, I investigate student outcomes under this intervention in two teachers' classrooms. In order to carefully inform my district's future policy and practice, I analyze specific instances of the complex relationships between implementing new instructional interventions, context, support for teachers, and achievement outcomes in an effort to better understand how this initiative may be influencing classroom practice and mathematics learning.

\section{Literature Review}

This study is grounded in three connected literature bases. First, I examine the setting of rural West Virginia, and explore any suggestions that this specific culture might make towards effective classroom practices. Next, I delve in to the history and best-practices of cooperative learning in math classrooms. Finally, where change is promising, instructional leaders should have care with how best to bring those promising practices to life in classroom. As such, this review of literature concludes with an exploration of the call for instructional coaching.

\section{Place-Based Need: An Examination of Setting}

This is a time where transition in United States mathematics classrooms is a lively topic. Experts in the field argue that change is needed in mathematics education on a large scale, and 
that progress in mathematics classrooms is an issue of security for the national economy (National Mathematics Advisory Panel, 2008). Recently, the Program for International Student Assessment ranked the United States below international averages in mathematics (PISA, 2013). Flexible problem-solving, as demonstrated through success on PISA items, requires an integration and flexibility of mathematics skills and understanding. This integrated and flexible knowledge of mathematics can be seen as a major goal of education and cognitive science (Star, 2015). The conversation about the shape of the change called for in teaching and learning mathematics is currently centered on the Common Core State Standards in Mathematics (CCSSM). These standards call for an even balance of procedural fluency, application, and conceptual understanding. They suggest building conceptual understanding, in part, through connections between multiple representations of big ideas. Furthermore, the Standards for Mathematical Practice (SMP) give a definition of mathematics and doing mathematics that asks students to explore and conjecture, critique and reason, and make and justify choices in their own problem solving (National Governors Association, 2010).

The reform-based instruction that is inherently called for by these standards is often a paradigm of teaching and learning mathematics that teachers did not experience themselves as students of mathematics (Green, 2014). As such, this is a time when all teachers in states adopting the CCSS-M must also see themselves as learners. The new practice standards dictate that it is important to use instructional models that encourage and elicit conceptual depth of thought (National Governors Association, 2010). The challenge of advancing the depth and efficacy of mathematics instruction is wide, deep and urgent.

Teaching and learning are unavoidably affected by local context and culture. The beauty of its mountains, depth of its culture and friendliness of its people characterize West Virginia. 
However, West Virginia also holds the challenges of systemic poverty, very rural school systems, and low teacher pay. Rural school systems hold unique challenges, including attracting and retaining highly qualified teachers (Arnold, 2004; Hammer et al., 2005; Monk, 2007), as well as difficulty retaining school administrators with the capacity and support to take on longterm and large-scale change in areas that are characterized as resistant to change (Lamkin, 2006). In addition, working in small rural schools can contribute to a sense of professional isolation in teaching staff, as well as a need for staff to assume multiple roles in school duties due to lack of staff (Hammer et al., 2005; Monk, 2007; Yettick et al., 2014). While rural schools generally measure up to their urban counterparts on standardized tests, they tend to offer fewer advanced classes and have a lower percentage of graduates who attend college (Arnold, 2004). Further, research has documented cases of student and community ambivalence about subjects that have the potential to lead students to seek careers that would lead them outside the community (Corbett, 2007; Hektner, 1995; Howley \& Hambrick, 2014; Ley et al., 1996).

In addition to rural systemic challenges, West Virginia is trailing most of the United States in achievement outcomes, particularly in mathematics. West Virginia has been amongst the last on lists of student achievement in mathematics by many measures (NAEP 2009, NAEP 2011, TIMMS 2014). Based on a meta-analysis of various data sources, Edweek recently ranked West Virginia schools with an overall score of " $C$ ", which translates to average. This 'average' score is misleading, however, as West Virginia ranked $46^{\text {th }}$ of 50 states in the categories of K-12 achievement and chance for success, and $50^{\text {th }}$ in mathematics excellence, as determined by the percent of students scoring advanced on the 2013 National Assessment of Educational Progress (Edweek, 2015). Relative to national averages, West Virginia contends with many challenges related to building strong educational experiences for her people. The state is behind national 
averages in percentage of the population with bachelor's degrees and median and per-capita incomes. West Virginia is ahead of the national averages in percent of the population living under the poverty level (Census, 2014). West Virginia leads the country in percent of workingage people on disability, with an adult population where less than half of its adult population work (Goldstein, 2015).

The sort of relative economic inequality to be found in the hills of West Virginia, as compared to national averages, is verified by scholars throughout the United States and is growing (Duncan \& Monroe, 2011). With a decline in the traditional coal industry, and no industry at the ready to take its place, income deficiencies of individuals as well as state funds will continue to decline. As educational research specific to rural Appalachia is limited, it makes sense to cast a wider net to learn more about the implications of such landscapes. Neuman and Celano's (2012) ten-year study of two Philadelphia economically diverse neighborhoods explores the difficult realities facing generationally low-income communities. They conclude that, while possible, the transition from dream to actualization of a life goal is becoming ever more difficult for children to realize in impoverished communities (2012). A parallel study of WV communities was not found, yet the central issue of potential implications of generational poverty mirrors well. A recent study from the Education Testing Service finds that the US, as a whole, has the widest gaps in achievement between the top and bottom $10 \%$ of the 22 countries studied. Differences between "haves" and "have-nots" in measures of financial as well as educational currency are big in our country and are getting bigger all the time.

To put it bluntly, we no longer share the growth and prosperity of the nation the way we did in the decades between 1940 and $1980 \ldots$ The disparity in private (as well as the public) investments made on behalf of children between different levels of 
[socioeconomic status] can be substantial, lasting, and self-perpetuating. (Goodman et al., 2015).

If education is to be an arbiter of the American Dream, one of the front lines can be found in West Virginia. With low academic outcomes, and huge generational economic barriers, the need is clear, but the path to realizing success is not. West Virginia, like many states, has sampled many promising educational interventions but has not seen lasting results. While there are many factors involved, a closer look at what sorts of interventions might be most effective in this particular setting is necessary, so analysis must take the role of place into account.

A search for a fitted educational approach might be informed by how attitude and achievement are related to one another. In the complex environment of teaching and learning mathematics, research suggests that it may be important to note whether an instructional approach positively influences students' attitude towards mathematics (Hannula, 2002; Ma, 1997). Some studies indicate that directional correlations are to be found between attitude toward mathematics and achievement in mathematics, as well as the converse relationship (e.g., Aiken, 1970; Anderson, 1981). Others believe that the relationship is not dependent in either direction, but rather is an interaction that is more complex (Ma, 1997; McLeod, 1992). Evidence suggests that a collaborative approach might promote more positive attitudes among students (Boaler, 1998; Ridlon, 1999). Dissecting the scope and nature of the relationship between attitudinal and achievement outcomes is beyond the scope of this work. However, as the two outcomes are generally believed to interact with one another, measuring attitude outcomes in tandem to achievement outcomes is important in ascertaining a full picture of the potential effects of a new instructional approach. 
A good fit of pedagogy to place and culture could well affect attitudes as well as outcomes. Teaching must be culturally relevant. Research articulates a roadblock to the efficacy of potential learning, even the introduction of barriers to learning, when there is a disregard for cultural relevancy (Hurley, Boykin \& Allen, 2005; Kennedy \& Aoteara, 2013; McCombs, 2000). In an attempt to answer these issues, textbook companies and teachers try to make mathematics meaningful through relevant application settings for mathematics problems. However, the educational setting itself can be a culture that contradicts learner identities. The APA LearnerCentered Psychological Principles maintain that the differences in learners' linguistic, cultural, and social backgrounds must be taken into account in order for learning to be effective (Presidential Task Force on Psychology in Education, 1993). Students in rural settings can experience a particular tension between their cultural identity and the aspirations of modern schooling, which can often not be realized in their home communities (Petrin et al., 2001). The interactions and implications of place, class and identity are complex. To create context, rural education scholar Corbett (2006) calls on two theorists: Pierre Bourdieu and Raymond Williams. Williams, coined the idea of "cultural materialism." He argues that culture is not a conception that is understood throughout history. Rather, the notion of culture was formed in the industrial age, and its modern meaning develops from economic origin. As such, culture both signifies a process, material products and a way of life (Milner, 2011). He further distinguished between aspects of cultural materialism as being emergent, residual, or dominant (Williams, 1985). Bourdieu studied the complicated relationship of power in society, and argued that social origin is a larger arbiter of all sorts of choices in life than are either educational or economic capital (Bourdieu, 1984). In other words, where we come from is hugely influential on what we choose and what works for us. Together, these thinkers 
...understand social class not only as a set of objective structures that matter, but more importantly as a complex of human and cultural dispositions, habits, algorithms for calculating life choices. These nuanced cultural practices are never routine and represent multiple ways of making distinctions, everyday judgments, and assessments of what matters and what is worth paying attention to. (Corbett, 2014, p 3).

Institutional schooling can bee seen defining success as overcoming much of what it means to be a rural Appalachian. In rural Appalachia, schools teach students to talk differently, know different things than their parents and grandparents do. This model of schooling doesn't teach or celebrate the things that Appalachian folks have taught and celebrated over the years music, stories, knowledge of nature and wildlife. The jobs that successful schooling prepares students for are often not found in rural places. Corbett illustrates the pull between rural cultures and a structure of schooling that actively disengages young people from their culture as a prerequisite for success. This construction of schooling is, therefore, pitting acceptance of and growth inside place, identity and self directly against success within the schooling system (Corbett, 2014). Howley, Howley and Yahn (2014) extend this thinking to suggest that institutional schooling was designed in a way that is not compatible with the strengths of rural places and communities. They suggest that either an institutional model of schooling is designed to fail in rural settings, or that rural settings will find a piece of their demise at the hands of our conception of successful schooling.

Given that the structures of public school in rural places are slow to change, the challenge remains to find ways to operate inside a flawed system that would better serve the needs of rural population. Perhaps some of the concerns that scholarship raises on the disconnect between rural cultures and the purpose, practice and conception of post-modern, neoliberal schooling could be 
better answered than they currently are. If so, it seems necessary to draw some of the strengths of the community into the classroom. Rural education researchers and thinkers have found this perplexing as well.

An authentically rural education... would respond to purposes that concerned rural ways of living, instead of rural-specific ways of teaching lessons considered universally appropriate. At the same time, however, rural education research itself has not seemedto the senior authors, over their careers - to engage very well what rural curriculum and teaching practice does require (Howley, Howley \& Yahn, 2014, p 2).

Perhaps, though, this is a false choice. Instead, rural educators might begin with understanding that ways of living, interacting and relating can be invited into classrooms and can be conceived as pathways to engaging in the teaching and learning of lessons (Howley \& Howley, 2015).

There has been markedly less scholarship on the resistance to schooling and learning styles of Appalachian rural youth than of urban youth (Hendrickson, 2012; Howley, Howley \& Yahn, 2014). Howley and Howley (2015) dig deeply into the question of place-based learning and teaching. If pedagogy is 'good', is it not 'good' everywhere? Furthermore, should we not follow the very best practices in the places, like many economically and academically disadvantaged rural communities, where the need for efficacy in classroom practice is the greatest? However, if the culture of rural communities is truly distinct from that of mainstream America, it is reasonable to question what the interplay might be of setting and effective structures for and paradigms of learning (Howley \& Howley, 2015).

Certain studies do raise important questions about what approaches to teaching and learning might be of particular promise in West Virginia. Rural students place a high value on a sense of community and family relationships, often giving more focus to the well-being of the 
family group than to individual achievement (Hendrickson, 2012; Howley \& Howley, 2015). Hendrickson's study looked closely at student resistance to schooling in Appalachia, citing one underlying cause as the difference in background, and so in values, between many middle-class teachers and high-percentage poverty students in the region. Howley and Howley (2015) explore this connection to family as a rural way of being that is not supported by the structures of schooling. Both suggest that the individualistic traditional approach of absorbing and reflecting skills might not be maximally inviting to these kids.

The central Appalachian region is an area characterized by high poverty, high drop-out rates, low college-completion rates, yet strong interpersonal bonds and a valued community engagement and identity (McHenry-Sorber, 2011). In the Appalachian region, a feeling of belonging in school may play a stronger role in student success than it does in the general population. In one Kentucky study, self-reported school connectedness has been found to be a better predictor of school performance amongst students from Appalachian region than from surrounding areas (Wilson \& Gore, 2009). In this study, performance was measured through GPA, while regional origin was coded by town of childhood as defined by the Appalachian Regional Commission's definition of Appalachia. A significant main effect of school connectedness was found, confirming the hypothesis that the association between GPA and school connectedness was stronger among people from Appalachia, as compared with students from other regions of Kentucky. This distinct cultural identity suggests that, coming from a culture that promotes collectivism over individualism, rural Appalachian youth may be particularly well-served by classroom structures and learning experiences that build upon this cultural call for connectedness. 
The implications of relevant literature illuminate the theme that there exist sub-cultures inside the United States that may differ in substantive ways from the mainstream culture, and therefore may benefit from approaches to pedagogical classroom moves and learning constructs that weave closer into the overarching cultural context than traditional, often more individualistic approaches to instruction. One possible instructional framework that might better align with rural cultures is a cooperative approach to learning.

\section{Cooperative Learning: History and Related Literature}

Cooperative learning is an approach to classroom management and a collection of strategies for teaching in which small teams, each with students of different levels of ability, use a variety of purposeful learning activities to improve their understanding of a subject. Team members are each responsible not only for learning what is taught but also for helping teammates learn, thus creating an atmosphere of interdependence and achievement. Implementing cooperative learning in a classroom differs from simply putting students in groups in that the structure of the class and the learning activities give greater focus to the interactions within groups of students (Johnson \& Johnson, 2009).

Cooperative learning has a long history in the United States (Johnson \& Johnson, 1994, Slavin 1989). Its uses can be traced back to the early 1800 s, and both theories and strategies for implementation can be found throughout the story of American educational thinking (Johnson \& Johnson, 1994). The model is rooted in the thinking of John Dewey, who focused more on the process of learning rather than the content (Sharan, 2010). Social psychologist Kurt Lewin further shaped today's theories of cooperative learning through the formalization of studying group dynamics and organizational psychology. Dewey and Lewin agreed that learning should be an active process, best pursued in collaboration and conversation with others. This thinking 
was formalized at the University of Chicago by Herbery Thelen, who developed a systemic strategy for learning in small groups (Sharan, 2010).

In the mid-1960s through early 1970s, both Johns Hopkins University and The University of Minnesota built K-12 teaching and learning programs around cooperative learning, and extended and articulated specific strategies to facilitate cooperation in the classroom. David and Roger Johnson at the University of Minnesota built a Cooperative Learning center, dedicated to developing, disseminating, researching and training best-practices in cooperative learning theory. They named their specific technique Learning Together (Slavin, 2012). Meanwhile, Johns Hopkins University developed the Teams-Games-Tournament approach (TGT), which later was further developed by Robert Slavin into the Student Team Achievement Division (STAD), where teams of students cooperate in competition with each other, and Team Assisted Instruction, a blend of cooperative teams and modified computer-assisted instruction (Johnson \& Johnson, 1994).

Hundreds of studies have been conducted since the 1970s on the effects of Cooperative Learning, indicating favorable outcomes on measures of achievement as well as attitude across disciplines (Davidson, 1985; Johnson \& Johnson, 1994; Slavin, 1980, 1989, 1996, 1999, 2012). The findings across these studies are quite consistent in nature, with several concluding that students develop better mathematics understandings, improve problem solving abilities, demonstrate improved attitudes towards school and towards mathematics. In addition, students with varied ability levels become more involved in task-related interactions (Davidson, 1990; Davidson \& Kroll, 1991; Leiken \& Zaslavansky, 1999; Weisglass, 1990). A meta-analysis of 800 studies suggested that students working in cooperative groups performed better on problem solving in part due to the generation of more strategies by students working cooperatively than 
by individuals working competitively (Qin et al., 1995). In a review of 80 studies on cooperative grouping in mathematics classes, students working in small groups significantly outperformed students working individually in more than $40 \%$ of the studies on mathematics tasks and assessments, while students working individually performed better in only two studies (Davidson, 1985).

While the overwhelming body of literature supporting Cooperative Learning as a framework is positive (Johnson \& Johnson, 1994; Slavin, 1980, 1989, 1996, 1999, 2012), deeper analyses paint a more nuanced picture of the conditions that must be met to realize positive benefits through this approach. Without a carefully monitored and implemented approach, learning teams can become ineffective and outcomes suffer as a result (Hsiung, 2014, Golub \& Buchs, 2014). For example, Hsuing's (2014) study of cooperative grouping in undergraduate engineering courses found that teams can become ineffective at any stage of the learning process, and require careful monitoring. Golub and Buchs' (2014) study found that more positive interactions were found when teachers gave explicit instruction for how and why students should work cooperatively. These positive interactions included students who displayed more support for one another, asked more questions, and paid more attention. Teachers who do not invest in teaching group processes and see cooperative learning as a 'magic bullet' can be easily frustrated, and give up on the process (Sharan, 2010).

Another vital piece to successful implementation of Cooperative Learning is the structure of the mathematical tasks assigned to students (Berry \& Sahlberg, 2006). There are some basic guidelines that ensure a 'group-worthy task' (Lotan, 2003; Sharan \& Sharan, 1992, as cited in Sharan, 2010). These include: 
- A clearly stated group goal that justifies two or more students learning together, formulated as a question that generates more than one answer and/or has more than one resource for the answer.

- Directions that activate positive interdependence, dividing the task so that each student has a distinct part in the search for the answer and/or in researching a source and can actively contribute to the completion of the task.

- Directions geared to the level of interpersonal skills group members have acquired and are comfortable with.

- Clear information about criteria for the evaluation of the learning content (Sharan, 2010, p.309).

In addition to potential pitfalls, differentiating between degrees of cooperation in experimental settings can be tricky and sometimes misleading (Slavin, Madden \& Leavey, 1984). Another confounding factor can be the treatment of the content inside the cooperative learning frame. One example of complex results comes from a study of fourth grade mathematics class using the Teams-Games-Tournament approach to cooperative learning. In the final analysis, the achievement outcomes of this 'high level' mathematics class fell short of results through previous years. The author posits that this under-realization of possibility may correlate with the procedural approach used by the teacher, which focused much more on the "how" than the "why" (Jacobs, 1999).

There is further recent work that supports the complexity of content, pedagogy, audience, and implementation on efficacy of cooperative learning techniques. Smith, McKenna and Hines (2014) investigated a large sample $(\mathrm{n}=7,377)$ of eighth-grade TIMMS data in order to investigate the relationship between frequency of group learning and achievement, as well as 
attitude towards mathematics. This study then analyzed interactive effects to determine whether gender moderates the relationship between group work and achievement or group work and attitude. Students were selected for the study in a two stage stratified sampling approach to ensure that data would be representative of the entire US population in terms of demographics, and to ensure that intact classes of students were chosen. TIMMS tests include student background surveys that include attitudinal scales to measure feelings about mathematics. In addition, students were asked how often they work in small groups, with possible responses of some lessons, about half of lessons, every lesson or almost every lesson, and never. Results indicated that students who participated in group work during some lessons or about half of lessons had significantly higher mathematics achievement scores than did students who did not use group work at all. Researchers also analyzed how attitudes towards mathematics are affected by frequency of group work. For every mathematics attitude outcome, students who engaged in group-learning activities showed significantly higher scores than those who never engaged in group work. Finally, authors analyzed the role of gender as a moderator on the relationship between group work and achievement, as well as group work and attitude. While no significant moderating effects were found for gender on the interaction between group work and attitude, there were significant findings for achievement. At the highest level of group work, girls outperformed boys in mathematics achievement, while boys outperformed girls in the classes where group work was never carried out. Study authors suggest that educators understand the positive achievement and attitudinal effects of moderate amounts of cooperative learning in mathematics classes, and make a further call for teachers to consider gender differences in learning style when planning instructional strategies (Smith, McKenna \& Hines, 2014). 
While there is scholarship to indicate that cooperative learning can produce positive effects on achievement within the general population, some research suggests that this effect is particularly of note among tribal populations and students of color (Hooker, 2011; Vaughn, 2002). In these studies, suggestions were drawn that the efficacy of cooperative learning might be increased in cultures that place high value on community and collectivism. As explored earlier, there is a distinct culture in Appalachia that values collectivism over individualism. Parallels might be drawn and interventions considered for Appalachian students from findings related to other student groups that share this cultural attribute. For example, Hurley, Boykin and Allen (2005) confirmed the earlier findings of Boykin (1994) that a critical mediator of children's performance can be the cultural context of their learning. In this study, Boykin's earlier work is referenced in making the case that communalism is an important theme in African American culture (Akbar, 1985; Boykin, 1986; Moemeka, 1998; as cited in Hurley, Boykin and Allen, 2005). In a study focused on African-American fifth-graders, students were split into two experimental learning conditions - one highly communal, utilizing group work and learning to the highest degree, and one minimally communal, utilizing more individual work. Students, in groups of threes, were given a 15-item pretest, 20 minute study period, then a 15-item mathematics-estimation test. Children in the cooperative learning framework significantly outperformed those in the individual learning framework. The authors assert that the learning environment that we create for children is a critical factor in determining how much and how well they learn, and that African American students would be well-served to experience more cooperative learning in mathematics classrooms (Hurley, Boykin and Allen, 2005).

Vaughn's semester-long study of cooperative learning in fifth-grade mathematics classrooms in Bermuda found significant differences in pre-and post-test scores for attitude and 
achievement in both computation and applications. This study did not include a control group, and so is not readily generalizable, but does support the conclusion that cultural context should be considered when choosing instructional approaches (Vaughn, 2002). In another study, similar results are found when studying the approach of cooperative learning in a developmental mathematics class at a Native American community college (Hooker, 2011). In this study the author examines how the use of small peer-led collaborative learning groups effect students' perceptions of mathematics as well as their success in mathematics class. The quasi-experimental study involved both quantitative and qualitative data. Results showed that use of peer-led cooperative learning structures had strong correlation with increases in perseverance and completion of mathematical tasks as well as an increase in attitude towards mathematics.

\section{Cooperative Learning: Best Practices and Approaches}

Using cooperative groups as an instructional framework should be intentional and research-based. Simply putting students in groups for academic practice does not produce desired outcomes. Instead, there are definitive pre-conditions that need to be met in order to realize the positive effects of cooperative learning. These conditions are: positive interdependence, individual accountability, promotive interaction, social skills and group processing (Johnson \& Johnson, 1994, 1998, 1999). In order to maximize positive outcomes, students need training on how to deal with issues as a group (Slavin \& Cooper, 1999) and teachers need training as well on how to best structure and facilitate student work in groups (Johnson \& Johnson, 2009).

A distinct difference in the Johns Hopkins (Slavin) and University of Minnesota (Johnson \& Johnson) camps of cooperative learning is that Slavin's work promotes a mixed model of cooperative learning where there is a distinct component of individual accountability, while 
Johnson \& Johnson promote a more "pure" version of cooperative learning, in that all learning and assessing happens inside the team or group. In a 1989 meta-analysis of the literature, Johnson and Johnson found that increases in achievement correlate with more "pure" versions of cooperative learning. Effect sizes in this analysis fell as the learning environment encompassed more competitive aspect (Johnson \& Johnson, 1989, as cited in 1994).

Student Teams-Achievement Divisions (STAD) is a structured framework for cooperative learning. This program has students work in 4-5 member heterogeneous teams during mathematics class, building inter-personal, mathematical and oral language skills simultaneously. Teachers follow an instructional framework of direct instruction, followed by guided group work and finally individual practice with support. Teams of students receive feedback on their team cooperation as well as their articulation of the structure and practice of mathematics. Teams are rewarded based on the performance of all team members. This team recognition and individual accountability is essential for positive achievement effects of cooperative learning (Slavin, 1995).

There is simply not sufficient literature on the effectiveness of cooperative learning in rural Appalachian mathematics classrooms. As such, literature on cooperative learning in studies centered on other sub-groups of students who share the cultural attribute of an emphasis and value on community and collectivism is drawn upon. Slavin's work $(1984,1989)$ gives a backdrop of success for the cooperative learning model, and raises the question: under what conditions does cooperative learning have the most efficacy in student achievement growth? Vaughn's work in 2002, together with Hurley, Boykin and Allen in 2005, suggests that students of color and African-American students, with deep roots of identity in communal success, as compared to individual success, may stand particularly benefit from this approach. Wilson and 
Gore (2009) establish that connectedness is particularly important for Appalachian students' academic success, creating a potential parallel between the needs of Appalachian students and students of color; both groups with rich tribal history and community identity in the United States and surrounding areas. The recent large-scale study of TIMMS data for $8^{\text {th }}$ graders concludes that cooperative grouping in mathematics class may help girls significantly, and seems to be beneficial to all learners in moderate contexts (Smith, McKenna \& Hines, 2014). Previous work spent more time investigating the benefit of cooperative learning models as compared to traditional classrooms, so this nuanced approach is of vital importance, indicating that, on the whole, students may do best with a balanced approach to instructional frameworks.

It is clear that there are some benefits, on the whole, of cooperative approach to learning. Additionally, efficacy of this learning approach depends upon how cooperative learning is implemented, the frequency with which it is implemented, and the cultural identities of the students involved. It is worth noting that cooperative learning seems at its most effective in subgroups that have not been as successful as average American white male students under the traditional, individual model of instruction.

Limitations certainly exist in this handful of research conclusions. As mentioned, Vaughn's work does not generalize, as random sampling wasn't employed, and there was no control (2002). The large-scale TIMMS study is compelling due to its sheer size, but there is no way of knowing how cooperative learning was understood, nor how it was implemented (Smith, McKenna and Hines, 2014). Students reporting group work could have meant many different things.

When implementing a cooperative learning approach for mathematics students in the Appalachian region, it will be crucial to be well-informed of the suggestions from the body of 
research literature. Specifically, it seems that educators should be encouraged to create a learning environment that develops in students how to operate effectively in teams, overtly instructs students on the value of helping behaviors, and well-balances cooperative learning with other models of inquiry and learning.

\section{Instructional coaching: How best to build system-wide change}

School transformation is not a menu that users can choose from. Once research has been done to identify a promising change for a particular school setting, there is still a long journey to translate the theory into reliable practice in classroom. As such, schools must attend to the professional development needs of their staff. There is a growing call for situating professional development for developing and changing teacher practice inside the context of teaching, as external approaches to improving instruction are rarely successful (Gallucci et al., 2010; Walters, 2014; Wei et al., 2009; Whitcomb et al., 2009;). Further, in order to make professional development for teachers most useful, content should focus on the concrete tasks of the classroom like teaching, assessment, observation and reflection (Wei et al., 2009; Hartman, 2013). Research suggests that one attribute of effective professional development is a collaborative learning environment and a collegial community of practice (Garet et al., 1999). Situating learning inside each teacher's own practice seems promising (Putnam \& Borko, 2000; Darling-Hammond \& McLaughlin, 1995). It is thought that professional development that is both substantial in number of contact hours and sustained over a long period of time will have greater impact on teaching practices (Garet et al., 1999).

Districts across the country are expanding their use of instructional coaching as a means to deliver this sort of job embedded professional development, and while literature base on practical experience is plentiful, there is limited peer-reviewed research to define the role, 
contexts, work or training of instructional coach (Walters, 2014; Gallucci et al., 2010). While instructional coaching is a wide-spread initiative of school districts, there is much variability in coaches' job descriptions and activities (Walters, 2014; Coskie et al., 2007). Variance also occurs in content of professional development, the degree to which the activities promote active learning on the part of the teacher-learners, and the extent to which the professional development activities are perceived as components of a coherent, connected program for teacher learning (Garet et al., 2001). As such, the coaching approaches would be wise to take such findings into account.

In summary, during this time of transition in all United States mathematics classrooms, it is more important than ever to use instructional models that engage students in authentic, deep learning. Student engagement and achievement have been shown to increase through ensuring that instructional processes are closely tied to the cultural context of students served (Jones, 2009). It is clear that some cooperative learning is helpful to all students, and that certain subgroups of students are helped markedly more than others by this learning framework. Students of Appalachian origin share the characteristic of strong community identity. Research from subgroups of students whose cultural ideals differ significantly in similar manner from the American cultural norm suggests the need for further study of well-designed cooperative learning as an effective learning model for Appalachian students.

\section{Objective}

In this study, I explored the effect of a cooperative learning framework and of structured, focused job-embedded instructional coaching on achievement among middle-school students in rural Appalachia. Particularly, I wanted to know: 
1. What is the value of implementing cooperative learning in rural mathematics classrooms in terms of its impact on student achievement? In other words: Does student achievement change over time in cooperative learning mathematics classrooms?

2. Does it matter how much support you give a teacher when implementing a cooperative learning approach? In other words: Is there an overall difference in achievement between these two classrooms?

3. What is the interaction between time and treatment on the effect of student achievement in mathematics? In other words: (A) Is there an overall difference in achievement between these two classrooms? and (B) What is the interaction between time and treatment on the effect of student achievement in mathematics?

\section{Method}

\section{Participants}

The study participants are 70 sixth-grade students attending two schools in the same rural WV district. Students are predominately white, with a rural Appalachian heritage and culture. The district at large is extremely rural, averaging just over 9 people per square mile with over $60 \%$ of land in state or federal forest. Communities have high levels of unemployment, high levels of drug addiction, high child poverty rates, and large distance from research-based highereducation institutions, as well as low levels of adults with a college degree. Nearly one-third of children live in poverty, with the child poverty rate at $29.5 \%$. Of adults over the age of 25 , only $43 \%$ hold a high school diploma, while only $11 \%$ have bachelor's degrees, and a mere 5\% hold graduate degrees (census.gov). The district is located in a county recently ranked amongst the highest for drug-related morbidity in the state (DHHR, 2015). Students in both schools have 
similar demographics of students, with over $60 \%$ free and reduced lunch annually. However, School 2 has approximately 1.75 times the students of School 1, with three smaller sixth grade mathematics classes $(15<\mathrm{N}<17)$ to School 1's single, relatively larger class $(\mathrm{N}=21)$. In order to hold a ratio of group sizes to 1.5 , necessary for meaningful statistical comparison of two data sets with normality violations, the co-taught class from School 2 that included all students with an Individualized Education Plan dictating special mathematics services was omitted from the study. School 1 had no students with this specified learning accommodation, and so no classes that were co-taught.

Each school has one sixth-grade mathematics teacher. School 2's sixth grade mathematics instructor, Mrs. B, has been teaching for 15 years. She has taught elementary multisubjects as well as middle school mathematics, where she's spent the last 8 years. She is fully certified to teach middle school mathematics. School 1's sixth grade mathematics instructor, Mrs. A, is in her second year of practice. Her certification does not include middle school mathematics, though she is actively working on coursework toward that certification. I am a participant in this project, serving as the district mathematics coach. I have worked with Mrs. A over the past two years, and Mrs. B over the past four. Work has included in-service and afterschool professional development (PD) on mathematics content and pedagogy, modeling in-class lessons, observing lessons and giving feedback.

Both schools in the district were included in an Investing in Innovation grant, which includes training and curricular materials for a cooperative learning approach in mathematics. School 2 is in its second year of implementation and support, while School 1 is in its first formal year of implementation. During year one, School 1 had informal access to the curriculum, but much smaller degree of support, and so did not have classrooms where students were 
consistently learning and interacting in groups. In the first year of implementation at School 1, while students were arranged in groups, the action of the class - the substance of the teaching and learning - remained between the teacher and individual students. Meanwhile, with more focus and support, School 2 made substantive progress towards turning the action of teaching and learning over to student teams during the first year of implementation. Over the course of this first year at School 2, lectures became shorter, teacher-led examples became fewer, and the teacher spent more time eliciting thinking and answering from groups than she did on direct instruction of mathematics. Over the course of this first year of implementation, School 1 had six coaching visits, while School 2 had more than twice that time with an instructional coach, as well as multiple peer observation opportunities and monthly after-school meetings. This study occurred over the course of the second year of implementation of cooperative learning, during which each school received 15 coaching visits, as well as monthly after-school professional development.

A typical coaching visit has five components. With individual teachers, focused observations include pre-and post-observation conferences. In addition, coaching visits to schools include modeling of pedagogical strategies or approaches to content. Finally, teachers participate in after-school learning community meetings that focus equally on group processing of classroom instructional strategies as well as activities that lead toward deepening teacher analysis of mathematics concepts and student understandings.

An individual pre-conference meeting gives context for a teacher's current personal goals and concerns, setting the stage for a classroom observation. During a classroom observation, I make notes that focus on the classroom teacher's goal. For example, if Mrs. B is working on monitoring and reinforcing productive mathematics talk during team time, I would focus my 
feedback accordingly. After the observation, a debriefing time with the teacher provides opportunity for immediate feedback. Together, we craft new goals for the following visit.

Finally, I will model, co-teach or substitute to allow the teacher to visit another classroom in a later class while the teacher observes and does a parallel critical note-taking process. Afterschool meetings allow teachers the opportunity to participate in a community of learners of both pedagogy and mathematics content. As such, our continuous improvement process for instruction is a group and collective process.

\section{Research Design}

The design of this study was quasi-experimental pretest/posttest. The dependent variable of achievement was measured using 4Sight, which is a Common Core-aligned benchmarking system intended to predict mastery on the Smarter Balanced Assessment. The treatment of cooperative learning was implemented over the course of the school year. Differences in pretest and posttest scores were analyzed using a repeated measures design ANOVA, detailed in Table 1.

Table 1

Synthesis of Research Questions and Analyses

\begin{tabular}{|l|l|l|}
\hline $\begin{array}{l}\text { Conceptual } \\
\text { Question }\end{array}$ & Research Question & Mixed Model ANCOVA \\
\hline $\begin{array}{l}\text { What is the value } \\
\text { of implementing } \\
\text { cooperative } \\
\text { learning in rural } \\
\text { mathematics } \\
\text { classrooms in } \\
\text { terms of its impact } \\
\text { on student } \\
\text { achievement? }\end{array}$ & $\begin{array}{l}\text { Does student achievement } \\
\text { change over time in } \\
\text { cooperative learning } \\
\text { mathematics classrooms, } \\
\text { independent of student } \\
\text { attitude towards } \\
\text { mathematics? }\end{array}$ & $\begin{array}{l}\text { Examination of the main effect } \\
\text { of time on student mathematics } \\
\text { achievement }\end{array}$ \\
& & \\
\hline
\end{tabular}




\begin{tabular}{|c|c|c|}
\hline \multirow{2}{*}{$\begin{array}{l}\text { Does it matter how } \\
\text { much support you } \\
\text { give a teacher } \\
\text { when } \\
\text { implementing a } \\
\text { cooperative } \\
\text { learning } \\
\text { approach? }\end{array}$} & $\begin{array}{l}\text { Is there an overall } \\
\text { difference between these } \\
\text { two schools? }\end{array}$ & $\begin{array}{l}\text { Examination of the main effect } \\
\text { of treatment on student } \\
\text { mathematics achievement }\end{array}$ \\
\hline & $\begin{array}{l}\text { What is the interaction } \\
\text { between time and treatment } \\
\text { on the effect of student } \\
\text { achievement in } \\
\text { mathematics? }\end{array}$ & $\begin{array}{l}\text { Examination of the interaction } \\
\text { between the main effects of time } \\
\text { and treatment on student } \\
\text { achievement }\end{array}$ \\
\hline
\end{tabular}

\section{Procedure}

Students, in heterogeneous groups of four or five, received instruction in cooperative group best-practices, as well as mathematics. The treatment of cooperative learning was implemented over the course of the school year. Teachers, supported by intensive professional development and coaching, delivered all instruction using a cooperative learning framework.

During class, students received instruction following the STAD model developed by Slavin (1989). Students received continual feedback from each other and from the instructor on concept development, skills and procedures, as well as being an effective member of a group. Lessons follow a daily structure. First students individually identify a mistake in a sample problem, then come to consensus with their team on the nature of the mistake and a correct problem-solving approach. A student is selected randomly to present to the class for an assessed individual grade as well as team points. Teams review homework collectively. Next, teachers instruct the topic of the day. After a minimal introduction, teams work cooperatively to solve a related problem, then the teacher moderates sharing of different solution pathways. Students then work individually on several problems, returning to their teams to debrief. Finally, students complete an exit slip as formative assessment for the following day's lesson. During the course of the class period, students can earn team points for team cooperation goals, including helping and encouraging others, thorough explanations, everyone participating, and completing tasks as a 
team. Team points accrue through a unit towards prizes like new pencils, bringing in music for class, and lining up first for lunch.

The class structure requires that teachers put the reins on 'helping' in order to first give students and teams an opportunity to struggle and persevere through problem solving difficulties. In addition, teachers need to manage class conversations and deepen their listening and questioning skills. During the course of this project, both teachers have monthly in-person coaching visits from me, as instructional coach. During these visits, each teacher has several observations and formative coaching sessions. In these sessions, teachers receive feedback and support in goal setting during individual coaching feedback sessions to continually refine their practice, then revisit and analyze their own growth cooperatively with me. Teachers also observe each other, as well as lessons that I model as instructional coach, taking a turn at giving instructional feedback. In addition, teachers attend monthly content and pedagogy support meetings. The teacher at school A had intensive instructional coaching during the school year prior to this study using this format, while the teacher at school B had only a handful of visits, with no opportunity for peer review and limited observational and modeling visits from the instructional coach.

The quantitative achievement component was measured through a benchmark given to students in September, December and March. The benchmark test was designed by the Success For All Foundation to replicate end-of-year Smarter Balanced Assessment, but does not yet have validity data as Common Core high stakes tests have not yet been given. Differences in achievement were analyzed using a repeated mixed-measures design ANOVA.

\section{ANOVA Assumption Examination}


The initial design of this study called for a repeated measures ANCOVA to examine (a) differences in benchmark scores, (b) differences in benchmark scores over time, and (c) differences in benchmark scores between the schools. The null hypothesis tested is that all means of benchmark scores are equal as a whole, over time, between schools and between schools over time.

There were several issues with assumptions for running the analysis as designed. First, the de-identified data set had several issues. There were 12 missing benchmark scores, accounting for $7 \%$ of the data set. These missing scores were distributed between the two schools among 10 students, and, for the most part, students with missing data were from School 1, with a smaller population $(\mathrm{N}=21)$ than school $2(\mathrm{~N}=32)$. One student was removed from the analysis, as a perfect score was reported, alongside two missing scores. No perfect score could be found among original data, so this anomaly was assumed a logical error and removed. ANOVA compares means, thus it made sense to replace each individual missing score with average score for each benchmark by school. In so doing, the mean of each benchmark for each school does not change, but the standard deviation would be lowered, perhaps resulting in falsely elevating the power of the statistical test.

Upon inspection of data sets, other ANOVA assumptions were met. ANOVA assumes a continuous dependent variable. The analysis also required that the within-subjects factor, the time of each benchmark, is categorical. These assumption were clearly met. In addition, ANOVA asks that there should be no significant outliers in the levels of the within-subjects factor. Inspection of Cook's Distances for each time period revealed all values $<1$, so this assumption was satisfied as well. 
ANOVA assumes that the distribution of the dependent variable, benchmark scores, in the three or more levels of the within-subjects factor, time, should be approximately normally distributed. Shapiro-Wilk (See Table 2) suggested that there are some issues with normality, and a visual inspection of histograms of each benchmark for each school revealed slightly platykurtic shapes. When standardizing scores for both skew and kurtosis, most values were well within one standard deviation from normally distributed values. The first two benchmarks at School 2 and the third benchmark at school 1 are positively skewed. The early benchmark positive skew would make sense, as this benchmark was assessing as a mock end of year test, so scores were clustered near the lowest end of possibilities. In addition, benchmark 3 at School 1 had positive kurtosis, indicating that this distribution was, indeed, platykurtic (see Table 3). However, since ANOVA is relatively robust to violations of normality, testing may proceed. Normality is an assumption that is close enough to being met, though a reduction in power is possible of any final result due in particular to the platykurtic nature of the third benchmark distribution for school 1 (Stevens, 2009).

Table 2

Tests of Normality

\begin{tabular}{|lccccccc|}
\hline & \multirow{2}{*}{ SchoolID } & \multicolumn{2}{c}{ Kolmogorov-Smirnov $^{\text {a }}$} & \multicolumn{3}{c|}{ Shapiro-Wilk } \\
\cline { 2 - 8 } & & Statistic & df & Sig. & Statistic & df & Sig. \\
\hline FirstBench & 1.00 & .150 & 20 & $.20{ }^{*}$ & .965 & 20 & .655 \\
\cline { 2 - 8 } & 2.00 & .159 & 32 & .038 & .917 & 32 & .017 \\
\hline SecondBench & 1.00 & .127 & 20 & $.20{ }^{*}$ & .948 & 20 & .344 \\
\cline { 2 - 8 } & 2.00 & .116 & 32 & $.20{ }^{*}$ & .913 & 32 & .014 \\
\hline ThirdBench & 1.00 & .218 & 20 & .013 & .881 & 20 & .018 \\
\cline { 2 - 8 } & 2.00 & .156 & 32 & .047 & .964 & 32 & .345 \\
\hline
\end{tabular}

*. This is a lower bound of the true significance. a. Lilliefors Significance Correction

\section{Table 3}

Standardized Skew and Kurtosis 


\begin{tabular}{|lrrrrrr|}
\hline School 1 & \multicolumn{1}{c}{ Skew } & Std error & Z score & Kurtosis & Std error & Z score \\
\hline Bench 1 & 0.20 & 0.51 & 0.39 & 0.14 & 0.99 & 0.14 \\
\hline Bench2 & 0.44 & 0.51 & 0.86 & -0.32 & 0.99 & -0.32 \\
\hline Bench 3 & 1.45 & 0.50 & 2.89 & 2.70 & 0.99 & 2.69 \\
\hline School 2 & & & & & & \\
\hline Bench 1 & 0.93 & 0.41 & 2.23 & 0.46 & 0.81 & 0.57 \\
\hline Bench2 & 0.10 & 0.41 & 2.40 & 0.81 & 0.81 & 1.00 \\
\hline Bench 3 & 0.58 & 0.41 & 1.41 & 0.04 & 0.81 & 0.05 \\
\hline
\end{tabular}

For an ANOVA test, homogeneity of variance is necessary across each group. Levene's test is not significant, $F(1,51)=3.14, p=.083$ for the first benchmark, $F(1,51)=.221, p=.640$ for the second benchmark, and $F(1,51)=1.56, p=.218$ for the third benchmark, indicating that this assumption is not violated. In addition to the assumptions of ANOVA, a repeated-measures ANOVA requires that the variances of the differences between all combinations of levels of the within-subjects factor must be equal, known as the assumption of sphericity. Mauchly's test of sphericity indicated that the assumption of sphericity had been met, $\chi^{2}(2)=3.514, p>.05$. Analysis can, therefore, proceed.

\section{Results}

Data are mean \pm standard deviation. The grand mean for benchmark scores over both schools was $31.61 \pm 1.60$.

Research Question 1: Does student achievement change over time in cooperative learning mathematics classrooms, independent of student attitude towards mathematics? Benchmark scores increased from $27.52 \pm 1.73$ in late September to $30.14 \pm 1.91$ in December to $37.15 \pm 2.05$ in March. Benchmark scores were statistically significantly different at the different time points during the school year, $F(2,100)=15.64, p<.001$, partial $\eta^{2}=.238$. This means that, overall, students showed growth as measured by this benchmark assessment over the course of the school year. 
Research Question 2: Is there an overall difference between these two schools? School 2 appeared to perform slightly better on all benchmarks with an average score of $37.15 \pm 2.51$ compared to School 1's average score of $30.08 \pm 1.98$. However, this result was not significant, as the confidence interval for the difference between the school's average benchmark scores included $0, M=3.05,95 \% C I[-3.37,9.48]$. Benchmark scores between the two schools were not statistically significantly different overall, $F(1,50)=.911, p=.344$, partial $\eta^{2}=.018$. There was no significant difference in overall scores between the two schools. In addition, the violations of normality had the possibility of increasing the likelihood of a Type-I error and attenuating the power of the ANOVA.

An examination of the data revealed the separate means on the benchmark measures for each of the schools. These scores are summarized in Table 4.

Table 4

Univariate statistics for variables in analysis (standard deviation)

\begin{tabular}{|lcccc|}
\hline Group & $\mathrm{N}$ & Benchmark 1 & Benchmark 2 & Benchmark 3 \\
\hline School 1 & 20 & $28.70(9.22)$ & $34.03(10.43)$ & $36.67(12.08)$ \\
\hline School 2 & 32 & $26.34(13.59)$ & $26.26(14.95)$ & $37.63(15.65)$ \\
\hline
\end{tabular}

Research Question 3: What is the interaction between time and treatment on the effect of student achievement in mathematics? ANOVA results reveal that benchmark scores between the two schools approached, but were not statistically significantly different over time, $F(2,100)=$ 3.072, $p=.051$, partial $\eta^{2}=.058$. As this result approached significance, further analysis was warranted.

When looking for differences between the two schools between benchmarks, no significant difference in growth between the first and third benchmarks is found, as indicated 
through the slopes of the line segments between average benchmark scores. However, School 2 had markedly more growth that School 1 between the second and third benchmarks. While there wasn't an overall difference between the schools, differences were observed between schools in the rate of learning, or the changes between benchmark scores over time. Figure1 gives a graph of marginal means for benchmark scores over time at each school, giving a picture of the different shapes of growth these schools experienced over the course of the school year.

Figure 1

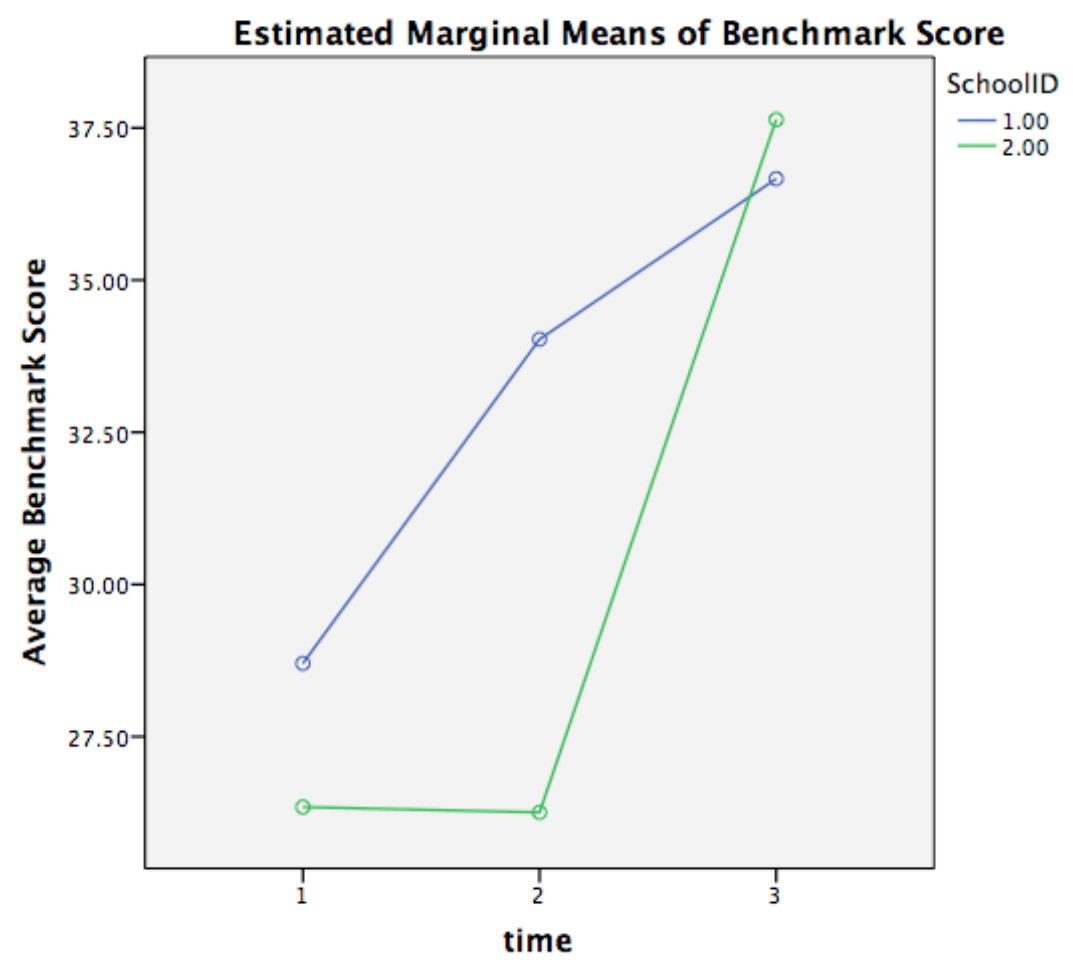

Table 4.

Synthesis of Research Questions and Results

\begin{tabular}{|l|l|l|l|}
\hline $\begin{array}{l}\text { Conceptual } \\
\text { Question }\end{array}$ & Research Question & Mixed Model ANCOVA & \multicolumn{1}{|c|}{ Result } \\
\hline $\begin{array}{l}\text { What is the value } \\
\text { of implementing } \\
\text { cooperative } \\
\text { learning in rural } \\
\text { mathematics }\end{array}$ & $\begin{array}{l}\text { Does student } \\
\text { achievement change } \\
\text { over time in } \\
\text { cooperative learning } \\
\text { mathematics }\end{array}$ & $\begin{array}{l}\text { Examination of the main } \\
\text { effect of time on student } \\
\text { mathematics achievement }\end{array}$ & $\begin{array}{l}\text { Yes, student } \\
\text { achievement grew } \\
\text { significantly over } \\
\text { time. There may be } \\
\text { value in }\end{array}$ \\
\hline
\end{tabular}




\begin{tabular}{|l|l|l|l|}
\hline $\begin{array}{l}\text { classrooms in } \\
\text { terms of its } \\
\text { impact on } \\
\text { student } \\
\text { achievement? }\end{array}$ & $\begin{array}{l}\text { classrooms, } \\
\text { independent of student } \\
\text { attitude towards } \\
\text { mathematics? }\end{array}$ & $\begin{array}{l}\text { implementing } \\
\text { cooperative learning } \\
\text { in rural mathematics } \\
\text { classrooms }\end{array}$ \\
\hline $\begin{array}{l}\text { Does it matter } \\
\text { how much } \\
\text { support you give } \\
\text { a teacher when } \\
\text { implementing a } \\
\text { cooperative } \\
\text { learning } \\
\text { approach? }\end{array}$ & $\begin{array}{l}\text { Is there an overall } \\
\text { difference between } \\
\text { these two schools? }\end{array}$ & $\begin{array}{l}\text { Examination of the main } \\
\text { effect of treatment on } \\
\text { student mathematics } \\
\text { achievement }\end{array}$ & $\begin{array}{l}\text { There is no overall } \\
\text { significant difference } \\
\text { between the two } \\
\text { schools. }\end{array}$ \\
\cline { 2 - 4 } & $\begin{array}{l}\text { What is the interaction } \\
\text { treatment on the effect } \\
\text { of student achievement } \\
\text { in mathematics? }\end{array}$ & $\begin{array}{l}\text { Examination of the } \\
\text { interaction between the } \\
\text { main effects of time and } \\
\text { treatment on student } \\
\text { achievement }\end{array}$ & $\begin{array}{l}\text { There are significant } \\
\text { differences in the } \\
\text { interaction of time } \\
\text { and treatment on } \\
\text { student achievement. }\end{array}$ \\
\hline
\end{tabular}

\section{Discussion}

In this study, my aim was to learn about the efficacy of cooperative learning on the under-studied Appalachian student population, as well as investigate how an increase in support for teachers might affect outcomes for students. I wanted to better understand effects of an intervention that would give teachers skills in managing instruction in a manner particularly well-suited to the dynamics of the cultural backbone of their children and classrooms. However, in the deeper study of both literature and quantitative measures - in comparing and contrasting these new understandings with my instincts from being in these classrooms -- a more nuanced picture emerged.

\section{Limitations}

The results of this study are necessarily limited in scope and implication due to the lack of a control group. That said, in the dynamic real-world setting of American classrooms, a sterile control group without any confounding factors will never be found. There were limitations in the design of this study. In addition to a lack of control, group sizes were small, and there was not a wide enough sample of teachers to really tease apart how support for implementing cooperative learning and outcomes may be connected. Complicating matters further, both the student 
populations and the classroom data between schools were uneven. Student data sets had missing pieces, emerging from the real and messy business of school.

These schools are not the same size. One has three sixth-grade mathematics classes and the other has only one. In order to bring the ratio of group sizes closer to the 1.5 threshold that makes analysis with ANOVA meaningful, one class of students at School 2 was removed from the study. It was necessary, therefore, to choose two of the three classes at the larger School 2. The omitted class had a co-teacher and contained students with documented special needs. On one hand, this omission made sense when comparing groups as Mrs. A had no students with documented special needs in mathematics, therefore no co-teacher in her class. On the other hand, such an omission hinders a holistic analysis of any intervention, as schools and interventions should benefit all students. It seems that special considerations should be given to those approaches or interventions that have potential to work particularly well for students whose needs are not always well-met, moving towards closing achievement gaps. There is anecdotal suggestion that this might be the case with cooperative learning in mathematics in this setting. Teachers in both schools at all grade levels (6-8) made note in their own analysis at the end of each of the two years of this intervention on the remarkable progress made by students with special needs in mathematics. In leaving out this class, which included students with special needs in mathematics, my analysis does not include some students who may have benefitted greatly from a well-implemented cooperative learning approach. It is possible that inclusion of all classes, and so all potential groups of student, in my analysis at School 2 would have led to greater, and more significant differences in changes in achievement scores over the course of the year between the two schools. 
The vastly different backgrounds of the two participating teachers played important roles that this study could not take into account. Mrs. A, in her third year of teaching at School 1, had one year of exposure to the curricular materials and approach but only limited support in transforming her classroom to a cooperative learning culture. She had more limited experience with different conceptual approaches to and student misconceptions about mathematics than the teacher at School 2. However, Mrs. A was working on her certification in middle school mathematics during this school year, so she was constantly exposed to further study of content and approaches to mathematics in middle school. Mrs. B, the veteran mathematics teacher at School 2, had relatively greater comfort with the content, as well a variety of solution approaches and pathways born from years of experience and training with a variety of curricula. With two years of coaching by the end of this study, Mrs. B. had developed a more comfortable and nuanced understanding of orchestrating student-centered cooperative learning in her classroom. This study sought to tease out the impact of this more refined approach. However, Mrs. B's relatively deeper comfort with and ease of content should not be overlooked in analysis, though it was beyond the scope of this study.

Finally, further analysis of 4Sight as a tool to measure mathematics achievement and predict performance on Smarter Balanced Summative Assessment (SBSA) is needed. There are significant concerns with assessing learning through a test that has not been seriously nor expertly vetted. The 4Sight benchmark used over the course of this study was designed to accompany this instructional program and was purported to predict proficiency on the SBSA Smarter Balanced Summative Assessment (SBSA). However, an informal comparison of 4Sight benchmark items alongside SBSA sample items does not show close alignment of approach nor of rigor. Further, with the first round of SBSA scores freshly in hand, we see a relatively large 
$7 \%$ difference in proficiency rates, favoring School 2, despite the inclusion of more students with special needs in mathematics. The 4Sight benchmark predicted equal percentages of proficient students at each school, under-predicting School 2's proficiency rates by five percentage points. In such small schools, these differences account for only a handful of students, but should nonetheless elicit some caution in ascribing meaning to 4Sight results until a wider study is done on this test's accountability and reliability.

This study demanded that I remove my first-hand knowledge of what is happening in classrooms from my analysis, which was strictly quantitative. As such, important perspectives were both gained and lost. Quantitative results were initially surprising to me. Without a lens limiting my view to only the quantitative measure of achievement, I would have been certain that the students in the more-supported classroom were, in fact, learning more. Their moreexperienced teacher had developed comfort with instructional moves that consistently and smoothly turned the reasoning over to students. When confronted with evidence that there was neither a clear nor a great difference between outcomes in these classrooms after three quarters of the year had passed, I had to wrestle with the dissonance between my expectation and the evidence in front of me. I had to ask the question, "Why would this outcome be true?"

\section{Interpretations}

Although the two schools preformed similarly on the final benchmark test in March, evidence of benchmark trends established in both schools prior to the final benchmark test suggest students at the two schools engaged in different patterns of learning over the course of the school year. After regressing a curve to fit the three available data points at each school, the rate of mathematics learning at School 1 appeared to be linear in shape, while the shape of mathematics learning at School 2 appeared exponential in shape. This study concluded its data 
collection with a March benchmark, while end of year summative SBSA was given in late May. Indeed, end-of-year SBSA results did suggest that, on average, students at School 2 (40\% proficient) were more successful in mastering the sixth-grade mathematical concepts, applications and procedures by the end of the year than were students at School 1 (33\% proficient). It is also worthwhile to note that both schools substantially out-performed the state average of $26 \%$ for sixth-grade mathematics proficiency, upsetting a trend in the district over the last five years to score consistently near or below the state average in math (wvde.state.wv.us/zoomwv).

If the learning trends suggested by the benchmark scores at each school continued until the end of the year and time for SBSA testing, it would make sense that School 2 would outperform School 1. The graph of the mean benchmark scores over time at each school (See Figure 1) reveals interesting trends that support the SBSA results, as well as my sense, as a frequent observer and instructional coach, of more student-centered cooperative learning happening at School 2. The literature on maximizing the efficacy of cooperative learning emphasized that teachers ought to make deep initial investment in group structures and strategies (Hsiung, 2014, Golub \& Buchs, 2014). Mrs. B started the school year with great focus on cooperative strategies and emphasized students learning cooperative routines. Mrs. A did not give equivalent focus to these skills and routines, instead moved more rapidly through the gradelevel content without the same initial focus on how teams were engaging each-other.

Upon reflection, these 'learning curves' make sense juxtaposed against the development of a cooperative learning classroom. In a more skilled practitioner's hands, time is taken early in the year to develop processes and habits conducive to efficacious team-work and rigorous team conversation. Teachers are coached to turn the thinking over to the kids. Initially, this is a great 
struggle for students who are used to getting attention and support from a teacher as soon as they feel confused. This adjustment is a major one for teachers as well. In a truly student-centered cooperative learning classroom, teachers coach teams to turn to one another and persevere through their problem-solving process. While students acclimate to this student-centered classroom culture, they will collectively struggle through a problem for extended periods of time before requesting support from a teacher. As teachers develop a greater fidelity to cooperative learning structures, they talk less, while students talk more. Fewer student hands go up over the course of a class, and students come to understand that doing mathematics can mean working to figure out even when you're not sure rather than repeating a procedure you're sure of. Teachers shift their definition of what a good mathematics class looks and sounds like, and students can become agents of their own learning, facilitating a steeper growth in achievement as time progresses.

Figure 1 could be illustrating a powerful difference in learning trends according to investment in, and adherence, to the principles of cooperative learning. Previously discussed limitations caution against definitive conclusions, but the suggestion that a deeper investment in implementing cooperative learning may give otherwise linear growth curves a more exponential shape is certainly powerful, and deserves future study.

There are multiple interpretations that could be drawn from the significantly different shape learning took over time in these two classrooms. It is possible that (a) the observed differences were connected to the differences in instructional coaching support for establishing and refining cooperative learning processes and practices, (b) the initial slower growth of School 2 was indicative of a teacher attending more to the process and procedures of the classroom than the mathematics at hand, or (c) there is no relationship between support for and differences in 
fidelity to a cooperative approach and the different shape of achievement growth. Due to the limitations of this study, however, definitive conclusions can not be drawn from among the possibilities.

That said, amongst the possibilities, the first rings true to my holistic view of these classrooms. When teachers are coached to focus on cooperative structures, initial growth in student achievement may be slower than in a traditional classroom. However, this initial investment may pay off in the long run as students untether their learning processes from the teacher, thus becoming more active in their own learning. Much more careful attention was given early in the year in School 2 to establishing routines of cooperative learning and to deepening student responsibility to learning and to each other as learners.

An alternate hypothesis would be that the initial attention to cooperative learning at School 2 unnecessarily slowed down learning for students, who otherwise would have mastered material earlier if the classroom were not so focused on these cooperative-learning processes. Given that Mrs. B gave extra attention to finessing the routines and structures of cooperative learning, it is possible that less of her attention was directed at the approach to the mathematics, and that her class could have achieved more had she not invested class time in group processes. All that said, there is no way to have confidence that the differences seen in the trend of learning growth over time between the schools are related to the difference in cooperative learning approach at all. In particular, it is not known how the different learning trends over time are affected by the nature of the differing backgrounds and conceptual mathematical approach of the teachers in this study, nor is it known if there was an underlying difference in these groups of students, who have been learning together in their small rural schools, forming a culture of learning and interacting over their school careers. 
I acknowledge all possibilities; yet consider them in the context of all I know about each of these schools. Formal summative assessment data over the years is available to me in my role as a participant in district mathematics work. While formally outside the scope of this analysis, this data can inform some of these questions. Of particular note, both schools' achievement levels in sixth-grade mathematics have been consistently below the state average over the past four years. Nether school consistently outperformed the other, though on average, scores at School 1 have been stronger. This year's summative assessment scores are well above the state average at both schools and are much stronger at School 2, so there is a substantive suggestion that the observed differences in learning trends over time at these schools could be connected to this cooperative learning-focused intervention. Rather than draw conclusions, however, the import of this study lies in framing an interesting question that should be asked: Across broader contexts, does learning over time take a fundamentally different shape as teachers finesse cooperative approaches in mathematics classrooms than the shape of learning in traditional mathematics class settings? If a larger study found that the shape of learning over time in cooperative learning classrooms is more exponential in shape than in traditional mathematics classes, this would inform the training process for teachers as well as administrators. Teachers could know that the early investment in processes to give students the ownership of the 'heavy lifting' of mathematics class is worthwhile. Further, the impact on student achievement of student-centered cooperative learning mathematics could range well beyond the school year, as students become more self-sufficient, persistent learners.

\section{Conclusions and Next Steps}

This study centered on a quantitative analysis of achievement benchmark data. However, the results in hand beg to be given a context; they ask for a qualitative look at what was 
happening inside these classrooms. It is difficult, if not impossible, to ascribe meaning to the difference in the shape of growth in mathematics achievement over the course of the study without having a window inside these classrooms. Further mixed-methods study would be helpful to better understand this dynamic so that a rigorous look at the action of classrooms might illuminate future quantitative findings.

There is potential power in placing a cooperative learning skill-set of strategies in the hands of mathematics teachers. As teachers invite and demand more engagement from students, classrooms feel more alive with learning. It seems possible that as students and teachers focus on adopting a new skill set, their attention turns from content toward pedagogy. As results from feedback with teachers, parents and students rolled in over the course of this study, I found myself compelled to shift my coaching time with teachers back to a focus on content, representations, and connections. As such, a better form of professional development might be one that constantly blends methods and content so that teachers can become more meta-cognitive in their practice. Teachers should be aware of how attending to one aspect of mathematics class might draw attention away from another. They should see how the eliciting, organizing and deep analysis of student reasoning both builds on and is built by deep attention to multiple perspectives on the "how," "why" and connections between the two. If teachers use these powerful cooperative strategies in a superficial treatment of mathematics, they miss the crucial opportunity that these strategies might offer our learning culture. Likewise, if teachers address the mathematics at hand in a powerful way with only direct instruction, or with only opportunity for a few students to respond during a class period, they miss the invitation for conceptual digestion in all students' minds. 
In the complex interplay of identity, place, pedagogy and educational reform, a few themes emerge. As an instructional leader, I want learners to be engaged, so I need to place a parallel focus on teachers as learners. It matters to think about the puzzles of learning in both scientific and personal ways. It matters that teachers learn not only how best to teach new content, but about how to help students learn how to actively learn, no matter the content. A parallel message holds for teachers as learners. Teachers need to learn content, but also must learn how students understand and misunderstand content. They need to learn pedagogy, and also how a pedagogy interacts with a place. Thus, teachers must be active tinkerers in their classrooms, noticing and reacting to if and how students engage with an approach, with content and with one another. Teachers must be engaged in the task of engaging students, rather than serve as passive recipients of strategies developed by outside experts. When I ask teachers to adopt new ways of being in classrooms, I need to take great care that I am, at the same time, building their agency.

Teachers can engage with implementing curriculum on a spectrum from passively to actively analytical. How they approach and implement this change is necessarily significant to outcomes of the approach (Thompson \& Usiskin, 2014). However, the administrative focus and support for a new approach in mathematics classrooms is equally important. How administrators and instructional leaders support teachers, and the degree to which that support takes place must be a powerful arbiter of outcomes. When school leaders take a scientific approach to implementing classroom change, they engage teachers as learners. As such, instructional leaders commit to their teachers' lives as thinkers themselves, and to a paradigm of learning and growth that is perpetual as well as pervasive. 


\section{References}

APA Work Group of the Board of Educational Affairs (1997). Learner-centered psychological principles: A framework for school reform and redesign. Washington, DC: American Psychological Association. Retrieved December 2, 2014 from http://www.apa.org/ed/governance/bea/learner-centered.pdf

Aiken, L. R., Jr. (1970). Attitudes toward mathematics. Review of Educational Research, 40(4), $551-596$.

Anderson, R. E. (1981). Measurement properties of attitude scales in the National Assessment of Educational Progress data on mathematics final report. Minneapolis: Minnesota Center for Social Research.

Arnold, M. (2004). Guiding Rural Schools and Districts: A Research Agenda. ED Pubs, P. Retrieved from http://eric.ed.gov/?id=ED484397

Berry, J. \& Sahlberg, P. (2006) Accountability affects the use of small group learning in school mathematics. Nordic Studies in Mathematics Education, 11, p.3-29.

Boaler, J. (1998). Open and closed mathematics: student experiences and understandings. Journal for Research in Mathematics Education, 29(1), 41-62. Retrieved from: http://doi.org/10.2307/749717

Bourdieu, P. (1984). Distinction: A social critique of the judgment of taste. Cambridge, Mass: Harvard University Press.

Corbett, M. (2009). Rural schooling in mobile modernity: Returning to the places I've been. Journal of Research in Rural Education, 24(7). Retrieved December 6, 2014 from http://jrre.psu.edu/ articles/24-7.pdf 
Corbett, M., \& Mulcahy, D. (2006). Education on a human scale: Small rural schools in a modern context (Research Report 061). Nova Scotia, Canada: Acadia Centre for Rural Education. Retrieved from:

https://www.researchgate.net/publication/264857742_Education_on_a_human_scale_Small_ rural_sc hools_in_a_modern_context

Coskie, T., Robinson, L., \& Autio, E. (2007). "Coach" Can Mean Many Things: Five Categories of Literacy Coaches in Reading First. National Center for Educational Evaluation and Regional Assistance, Institute of Education Sciences, US Department of Education.

Darling-Hammond, Linda, and Milbrey W. McLaughlin. "Policies that support professional development in an era of reform." Phi delta kappan 76.8 (1995): 597-604.

Davidson, N. "Small group learning and teaching in mathematics: A Selective Review of the Research.” In R. Slavin (ed.) Learning to Cooperate, Cooperating to Learn. New York: Plenum Press, 1985.

Davidson, N. “Small-Group Cooperative Learning in Mathematics.” In T. Cooney and C. Hirsch (eds.) Teaching and Learning Mathematics in the 1990s. Reston (VA): NCTM, 1990.

Davidson, N. and Kroll, D. “An Overview of Research on Cooperative Learning Related to Mathematics." Journal for Research in Mathematics Education. November 1991, 22: 362365.

desJardins, M., \& Martin, S. (2013). CE21-Maryland: The state of computer science education in Maryland high schools. Retrieved from http://ce21maryland.umbc.edu/files/2013/01/sig218- desjardins.pdf 
Gallucci, C., Van Lare, M. D., Yoon, I. H., \& Boatright, B. (2010). Instructional coaching: Building theory about the role and organizational support for professional learning. American Educational Research Journal, 47(4), 919-963.

Garet, Michael S., et al. "Designing Effective Professional Development: Lessons from the Eisenhower Program [and] Technical Appendices." (1999).

Garet, M. S., Porter, A. C., Desimone, L., Birman, B. F., \& Yoon, K. S. (2001). What makes professional development effective? Results from a national sample of teachers. American educational research journal, 38(4), 915-945.

Goldstein, S. (n.d.). The only state where less than half its civilians work. Retrieved February 14, 2015, from http://www.marketwatch.com/story/this-is-the-only-state-where-less-than-halfits-citizens-work-2015-01-13

Goodman, M., Sands, A. M., \& Coley, R. J. (2015). America's skills challenge: millennials and the future. Retrieved August 1, 2015 from https://www.ets.org/s/research/30079/ascmillennials-and-the-future.pdf

Green, E. (2014). Why do Americans Stink at Math? The New York Times. Retrieved August 1, 2015 from http://www.nytimes.com/2014/07/27/magazine/why-do-americans-stink-atmath.html

Hammer, P. C., Hughes, G., McClure, C., Reeves, C., \& Salgado, D. (2005, December). Rural teacher recruitment and retention practices: A review of the research literature, national survey of rural superintendents, and case studies of programs in Virginia. Charleston, WV: AEL, Inc. Retrieved from http://files.eric.ed.gov/fulltext/ED489143.pdf

Hannula, M. S. (2002). Attitude towards mathematics: emotions, expectations and values. Educational Studies in Mathematics, 49(1), 25-46. 
Hartman, S. (2013). Mathematics Coaching in a Rural School: Gaining Entry: A Vital First Step. Journal Of Education, 193(1), 57-67.

Hendrickson, K. A. (2012). Student Resistance to Schooling: Disconnections With Education in Rural Appalachia. High School Journal, 95(4), 37-49.

Hektner, J. M. (1995). When moving up implies moving out: Rural adolescent conflict in the transition to adulthood. Journal of Research in Rural Education, 11(1), 3-14.

Hooker, D. (2011). Small Peer-Led Collaborative Learning Groups in Developmental Mathematics Classes at a Tribal Community College. Multicultural Perspectives, 13(4), 220226. doi:10.1080/15210960.2011.616841

Howley, C. W., \& Hambrick, K. (2014). Getting there from here: Schooling and rural abandonment. In C. B. Howley, A. A. Howley, and J. Johnson (Eds.), Dynamics of Social Class, Race, and Place in Rural Education (pp. 193-216). Charlotte, NC: Information Age Publishing.

Howley, C.B., Howley, A., \& Yahn, J. (2014). Motives for dissertation research at the intersection between rural education and curriculum and instruction. Journal of Research in Rural Education, 29(5), 1-12.

Howley, C. W., \& Howley, C. B. (2015). Farming the children of the poor at the schoolhouse door. In Reforming schools in the age of neoliberalism (pp. 23-52). Boston: Sense Publishers.

Hsiung, C.M., Luo, L.F. and Chung, H.C. (2014), Early identification of ineffective cooperative learning teams. Journal of Computer Assisted Learning, 30: 534-545.

Johnson, D. W., \& Johnson, R. T. (1999). Making Cooperative Learning Work. Theory into Practice, 38(2), 67-73. 
Johnson, D. W., Johnson, R. T., \& Holubec, E. J. (1994). New Circles of Learning : Cooperation in the Classroom and School. Alexandria, VA, USA: Association for Supervision \& Curriculum Development (ASCD). Retrieved from http://www.ebrary.com

Johnson, D. W., \& Johnson, R. T. (2009). An Educational Psychology Success Story: Social Interdependence Theory and Cooperative Learning. Educational Researcher, 38(5), 365379. doi:10.3102/0013189X09339057

Jones, R. (2009). Strengthening student engagement. Rexford, NY: International Center for Leadership Education. Retrieved from http://www.leadered.com/pdf/Strengthen\%20Engagement $\% 20$ White\%20 paper.pdf

Lamkin, M. L. (2006). Challenges and Changes Faced by Rural Superintendents. Rural Educator, 28(1), 17-24.

Leiken, R. and Zaslavasky, O. “Cooperative Learning in Mathematics.” Mathematics Teacher. March 1999, 92: 240-246.

Ley, J., Nelson, S., \& Beltyukova, S. (1996). Congruence of aspirations of rural youth with expectations held by parents and school staff. Journal of Research in Rural Education, 12(3): 133-141.

McHenry-Sorber, E. C. (2011). Competing values, competing narratives: Rural education politics in dual arenas (Ph.D.). The Pennsylvania State University, United States -Pennsylvania. Retrieved from http://search.proquest.com.www.libproxy.wvu.edu/docview/926811355/abstract/C8B42849B $\underline{633436 \mathrm{CPQ} / 4 \text { ?accountid }=2837}$ 
McLeod, D. B. (1994). Research on Affect and Mathematics Learning in the JRME: 1970 to the Present. Journal for Research in Mathematics Education, 25(6), 637-647. Retrieved from: http://doi.org/10.2307/749576

Milner, A. (2011). Williams, Raymond. In M. Ryan (Ed.), The encyclopedia of literary and cultural theory. Hoboken, NJ: Wiley. Retrieved from http://www.libproxy.wvu.edu/login?url=http://search.credoreference.com.www.libproxy.wvu .edu/content/entry/wileylitcul/williams_raymond/0

Monk, D. H. (2007). Recruiting and retaining high-quality teachers in rural areas. The Future of Children, 17(1), 155-174. Retrieved from http://files.eric.ed.gov/fulltext/EJ795884.pdf National Governors Association Center for Best Practices, \& Council of Chief State School Officers. (2010). Common Core State Standards. Washington, DC: Authors.

Oakley, B. (2003). Coping with hitchhikers and couch potatoes on teams. Retrieved July 29, 2014, from http://www.public.iastate.edu/ goodwin/spcom322/coping.pdf

Peurach, D. J. (2011). Seeing complexity in public education: problems, possibilities, and success for all. Cary, NC, USA: Oxford University Press, USA. Retrieved from http://www.ebrary.com

Putnam, Ralph T., and Hilda Borko. "What do new views of knowledge and thinking have to say about research on teacher learning?." Educational researcher (2000): 4-15.

Quality Counts 2015: State Report Cards Map - Education Week. (2015, January 8). Education Week. Retrieved from http://www.edweek.org/ew/qc/2015/2015-state-report-cardsmap.html?intc=EW-QC15-TOC

Qin, Z., Johnson, D. and Johnson, R. “Cooperative Versus Competitive Efforts and Problem Solving." Review of Educational Research. Summer 1995, 65: 129-143. 
Sharan, Y. (2010). Cooperative learning for academic and social gains: valued pedagogy, problematic practice. European Journal Of Education, 45(2), 300-313. doi:10.1111/j.14653435.2010.01430.x

Slavin, R.E. (2012). Cooperative learning. In Banks, J. A. (Ed.). (2012), Encyclopedia of Diversity in Education (pp 434-442). Thousand Oaks, CA, USA: SAGE Publications, Inc. Retrieved from http://www.ebrary.com

Slavin, R. E. (1996). Cooperative learning in middle and secondary schools. Clearing House, 69(4), 200.

Slavin, R. E., Lake, C., \& Groff, C. (2009). Effective programs in middle and high school Mathematics: A Best-Evidence Synthesis. Review of Educational Research, 79(2), 839-911. doi:10.3102/0034654308330968

Slavin, R. (2008). Education reform requires teachers to apply research-proven methods. Education Journal, (110), 7-10.

Slavin, R. E., \& Cooper, R. (1999). Improving intergroup relations: Lessons learned from cooperative learning programs. Journal of Social Issues, 55(4), 647-663.

Slavin, R. E., Madden, N. A., \& Stevens, R. J. (1989). Cooperative learning models for the 3 R's. Educational Leadership, 47(4), 22.

Slavin, R. E. (1999). Comprehensive approaches to cooperative learning. Theory Into Practice, $38(2), 74$.

Slavin, R. E. (1980). Cooperative learning. Review of Educational Research, 50(2), 315-342. doi:10.2307/1170149 
Smith, T., McKenna, C., \& Hines, E. (2014). Association of group learning with mathematics achievement and mathematics attitude among eighth-grade students in the US. Learning Environments Research, 17(2), 229-241. doi:10.1007/s10984-013-9150-x

Star, J. R., Pollack, C., Durkin, K., Rittle-Johnson, B., Lynch, K., Newton, K., \& Gogolen, C. (2015). Learning from comparison in algebra. Contemporary Educational Psychology, 404154. doi:10.1016/j.cedpsych.2014.05.005

Stern, J. D. (1994). The Condition of Education in Rural Schools. U.S. Government Printing Office, Superintendent of Documents, Mail Stop: SSOP, Washington, DC 20402-9328. Retrieved from http://eric.ed.gov/?id=ED371935

Thompson, D. R., Usiskin, Z. (2014). Enacted mathematics curriculum: A conceptual framework and research needs. Charlotte, North Carolina: IAP, Information Age Publishing, Inc. Vaughan, W. (2002). Effects of Cooperative Learning on Achievement and Attitude Among Students of Color. Journal of Educational Research, 95(6), 359.

Walters, K. (2014). Instructional Coaching Strategies to Support Student Success in Algebra I. Retrieved from https:/www2.ed.gov/programs/dropout/instructionalcoaching092414.pdf Whitcomb, J., Borko, H., \& Liston, D. (2009). Growing Talent. Journal of Teacher Education, 60(3), 207-212.

Wei, R. C., Darling-Hammond, L., Andree, A., Richardson, N., \& Orphanos, S. (2009). Professional learning in the learning profession: A status report on teacher development in the United States and abroad: Technical report. Dallas, TX: National Staff Development Council. Retrieved from www.nsdc.org/ stateproflearning.cfm 
Weissglass, J. “Cooperative learning using a small group laboratory approach: cooperative learning in mathematics.” In N. Davidson (ed.) Cooperative Learning in Mathematics: A Handbook for Teachers. Menlo Park (CA): Addison- Wesley, 1990.

West Virginia Earns a C on State Report Card, Ranks 27th in Nation - Education Week. (2015, January 8). Quality Counts. Retrieved from http://www.edweek.org/ew/qc/2015/statehighlights/2015/01/08/west-virginia-education-ranking.html

Williams, R., \& Ebooks Corporation. (1985). Keywords: A vocabulary of culture and society. New York: Oxford University Press.

Wilson, S., \& Gore, J. (2009). Appalachian origin moderates the association between school connectedness and gpa: Two exploratory studies. Journal of Appalachian Studies, 15(1/2), 70-86.

NCLB and the demand for highly qualified teachers: Challenges and solutions for rural schools ProQuest. (n.d.). Retrieved August 27, 2015, from http://search.proquest.com/openview/774d026d14d81b8e5c722e08198d3647/1?pqorigsite $=$ gscholar 